\title{
Optimal Initial Perturbations for Ensemble Prediction of the Madden-Julian Oscillation during Boreal Winter
}

\author{
YOO-GEUN HAM \\ Global Modeling and Assimilation Office, NASA Goddard Space Flight Center, and Goddard Earth Sciences Technology \\ and Research Studies and Investigations, Universities Space Research Association, Greenbelt, Maryland \\ SIEGFRIED SCHUBERT \\ Global Modeling and Assimilation Office, NASA Goddard Space Flight Center, Greenbelt, Maryland \\ YEHUI CHANG \\ Global Modeling and Assimilation Office, NASA Goddard Space Flight Center, and Goddard Earth Sciences \\ Technology and Research, Morgan State University, Baltimore, Maryland \\ (Manuscript received 22 June 2011, in final form 27 January 2012)
}

\begin{abstract}
An initialization strategy, tailored to the prediction of the Madden-Julian oscillation (MJO), is evaluated using the Goddard Earth Observing System Model, version 5 (GEOS-5), coupled general circulation model (CGCM). The approach is based on the empirical singular vectors (ESVs) of a reduced-space statistically determined linear approximation of the full nonlinear CGCM. The initial ESV, extracted using 10 years (1990-99) of boreal winter hindcast data, has zonal wind anomalies over the western Indian Ocean, while the final ESV (at a forecast lead time of 10 days) reflects a propagation of the zonal wind anomalies to the east over the Maritime Continent-an evolution that is characteristic of the MJO.

A new set of ensemble hindcasts are produced for the boreal winter season from 1990 to 1999 in which the leading ESV provides the initial perturbations. The results are compared with those from a set of control hindcasts generated using random perturbations. It is shown that the ESV-based predictions have a systematically higher bivariate correlation skill in predicting the MJO compared to those using the random perturbations. Furthermore, the improvement in the skill depends on the phase of the MJO. The ESV is particularly effective in increasing the forecast skill during those phases of the MJO in which the control has low skill (with correlations increasing by as much as 0.2 at 20-25-day lead times), as well as during those times in which the MJO is weak.
\end{abstract}

\section{Introduction}

Since its discovery about three decades ago, the Madden-Julian oscillation (MJO; Madden and Julian 1971) has been the subject of numerous studies to better characterize its behavior and ascertain the underlying physical mechanisms at play (e.g., see the review by Zhang 2005). Also, in recognition of the important impact of the MJO on weather and climate variability on subseasonal time scales (Yasunari 1979; Takayabu et al. 1999; Bergman et al. 2001; Kessler 2001; Wheeler and McBride

Corresponding author address: Dr. Yoo-Geun Ham, NASA Goddard Space Flight Center, Code 610.1, Greenbelt, MD 20770. E-mail: yoo-geun.ham@nasa.gov
2005), there is an increasing emphasis on efforts to assess its predictability and develop better prediction methods. Statistical methods have had some success in predicting the MJO (Waliser et al. 1999; Lo and Hendon 2000; Mo 2001; Jones et al. 2004; Webster and Hoyos 2004; Maharaj and Wheeler 2005; Jiang et al. 2008) and provide an important benchmark for dynamically based approaches that, owing to the poor simulation of the MJO, have generally failed to improve upon such simpler approaches (Slingo et al. 1996; Waliser et al. 2003a,b; Zhang 2005; Waliser 2006). However, recent improvements in general circulation models (GCMs) including a better simulation of subseasonal tropical variability (Slingo 2005; Wu et al. 2002; Seo et al. 2009a), have renewed interest in using GCMs to predict the MJO (Vitart et al. 2007; 
Seo et al. 2005, 2009b; Kang and Kim 2010; Rashid et al. 2011).

The skill of MJO predictions has been assessed using various air-sea coupled models. For example, Vitart et al. (2007) showed that the European Centre for MediumRange Weather Forecasts (ECMWF) coupled model is skillful in predicting the evolution of the MJO up to about 14 days, and Seo (2009) and Seo et al (2009) showed that the National Centers for Environmental Prediction (NCEP)'s operational coupled Climate Forecast System (CFS) model exhibits useful skill out to 2 and 3 pentads when the initial MJO convection is located over the Maritime Continent and the Indian Ocean, respectively. In addition, Rashid et al. (2011) found that the MJO can be predicted using the Predictive Ocean-Atmosphere Model for Australia (POAMA) with 10 ensemble members out to about 21 days. Kang and Kim (2010) compare the skill of MJO predictions using both statistical models and the Seoul National University (SNU) CGCM and concluded that the limit of skillful predictions made with statistical (multivariate regression) models based on the Real-Time Multivariate Madden-Julian oscillation (RMM) index occurs at days 16-17, while it occurs at about 20 days for the GCM.

As a part of the ensemble prediction system, it is known that the prediction skill is dependent the structure of the ensemble perturbations (Toth and Kalnay 1993). However, while there has been progress in predicting the MJO associated with model improvements, there has been less emphasis on the issue of how to best (from the stand point of predicting the MJO) perturb the initial conditions of the ensemble prediction system. For example, in several studies the predictions consist of only a single ensemble member-mainly because of the heavy computational burden of generating hindcasts over a period of two decades (Kang and Kim 2010), or, the initial perturbation is not focused on the MJO. Vitart et al. (2007) and Vitart and Molteni (2010) used singular vectors (an optimal perturbation method) to perturb the extratropics (north of $30^{\circ} \mathrm{N}$ ), since their focus was on weather forecasts. Rashid et al. (2011) performed ensemble predictions in which the atmospheric "perturbations" are based on the atmospheric analyses $6 \mathrm{~h}$ before the start time. The method is called lagged averaged forecasting (LAF; Hoffman and Kalnay 1983) and provides an alternative to adding random perturbations. It turns out that this method partly captures the features of so-called optimal perturbations.

To extract the optimal perturbations for ensemble MJO prediction, Liess et al. (2005) adopted a breeding approach to generate initial perturbations suitable to the MJO prediction within a perfect model framework. They defined the rescaling time as the pentad at which detection of the modes that grow fastest on the intraseasonal time scale is achieved, without being influenced too strongly by higher-frequency weather instability. Similarly, Chikamoto et al. (2007) successfully extracted the tropical-bred vectors associated with the MJO with a one-day rescaling interval. The extracted bred vectors show eastward propagation, which begins over the Indian Ocean and becomes prominent over the western Pacific. This feature resembles the MJO, suggesting that breeding methods are suitable for extracting optimal perturbations for MJO prediction. However, that study did not perform an ensemble of MJO predictions with their perturbations to fully validate the importance of optimal perturbation for improving MJO prediction skill.

Motivated by the above facts, this study re-examines the optimal perturbations for MJO prediction using an empirical singular vector (ESV; Kug et al. 2010, 2011; Ham and Kang 2010) approach, applied to an ensemble prediction system for boreal winter season. The basic concept of the ESV method is similar to the singular vector method, which is widely used in weather forecasts (Molteni and Palmer 1993; Palmer et al. 1994). The main difference between ESV and the singular vector method is that the ESV method does not require a linearized version of a GCM. Instead, the ESV is calculated using historical prediction data-something that is becoming more widely available for GCMs as an integral component of model evaluation and calibration. Therefore, the ESV method is more easily applicable to various GCMs without the need for a linearized version of the model. In addition, unlike the breeding method, it is relatively easy to extract optimal perturbations related to the MJO without additional model integrations during the forecasts.

This paper is organized as follows. In section 2, the Goddard Earth Observing System Model, version 5 (GEOS-5) CGCM developed at the National Aeronautics and Space Administration (NASA) Global Modeling and Assimilation Office (GMAO) is briefly described, and the initialization for the hindcasts and the empirical singular vector method is introduced. Section 3 describes the experimental design of the hindcasts and the forecast skill improvements associated with the use of the ESVs. The discussion and brief summary are included in section 4 .

\section{Model and hindcast experiments}

\section{a. NASA/GMAO GEOS-5 coupled GCM}

The model used in this study is the NASA/GMAO GEOS-5 Coupled General Circulation Model (CGCM). The ocean component of NASA/GMAO GEOS-5 CGCM is the Modular Ocean Model version 4 (MOM4) 
code (Griffies et al. 2004). The ocean model uses a $B$-grid finite difference treatment of the primitive equations of motion, Boussinesq and hydrostatic approximations in spherical coordinates, and covers the global oceans with realistic coastlines and bathymetry. The resolution is 50 vertical levels and a $1^{\circ} \times 1^{\circ}$ horizontal grid telescoping to $1 / 3^{\circ}$ meridional spacing near the equator. The vertical grid spacing is a constant $10 \mathrm{~m}$ over the top $225 \mathrm{~m}$. The $K$-Profile Parameterization (KPP) vertical mixing scheme is used in this model.

The atmospheric component of the GEOS-5 model used here has 72 vertical levels and $2^{\circ}$ latitude by $2.5^{\circ}$ longitude grid spacing. The dynamic core is based on a finite-volume method (Lin 2004). The convective parameterization is the relaxed Arakawa-Schubert (RAS) scheme (Moorthi and Suarez 1992). The large-scale condensation scheme is based on a PDF of total water as in Smith (1990) or Rotstayn (1997). The free atmospheric turbulent diffusivities are based on the gradient Richardson number. For the boundary layer, the Louis (1982) scheme is implemented in stable situations with no or only weak cooling in the planetary boundary layer (PBL) cloud. In addition, the Lock et al. (2000) scheme is used for unstable or cloud-topped PBLs. GEOS-5 incorporates two gravity wave drag parameterizations, an orographic gravity wave drag formulation (McFarlane 1987), and a formulation for nonorographic waves based on Garcia and Boville (1994). The Catchment Land Surface Model from Koster et al. (2000) is coupled to atmospheric model. Air-sea fluxes are exchanged at every time step. More details about the GEOS-5 atmospheric model are provided in Rienecker et al. (2007).

\section{b. Initialization for the MJO forecasts}

We perform the MJO hindcasts from 1990 to 1999 using the GEOS-5 CGCM. The atmosphere-ocean initial conditions for this period are obtained by constraining the atmospheric component (i.e., zonal and meridional wind, temperature, specific humidity, and surface pressure) of the CGCM with the Modern-Era Retrospective Analysis for Research and Applications (MERRA; Rienecker et al. 2011) using an incremental analysis update procedure (IAU; Bloom et al. 1996) beginning in 1979. We refer to this as a "replay" approach since it makes use of an existing atmospheric analysis. ${ }^{1}$ Even

\footnotetext{
${ }^{1}$ The IAU method was originally developed to be part of a data assimilation procedure to reduce the shocks of data. The replay approach works in the same way except that it uses an existing analysis (in this case MERRA) to compute the increments. We note that the IAU is different from the traditional nudging approach in that the IAU filters the analysis increments only and not the full background state (Bloom et al. 1996).
}

though the replay approach, directly, only constrains the atmospheric component of the coupled model, the upper ocean is also adjusted to the observed values via air-sea coupling, even without the assimilation of any subsurface ocean observations. In particular, it is found that the subsurface tropical temperature anomalies from the surface to $300 \mathrm{~m}$ in the replay simulation are quite similar to those obtained from ocean reanalyses (e.g., Behringer and Xue 2004; Carton and Giese 2008) (not shown).

With these initial conditions, we perform 30-day MJO hindcasts every day for the period $1990-99 .^{2}$ This "control (CNTL)" set of predictions is used to compute the ESVs and also serves as part of the benchmark against which to evaluate the MJO prediction skill of hindcasts that use ESV-based perturbations (see next section).

\section{c. Description of the ESV}

The ESV method used in this study follows the procedure described in Kug et al. (2010, 2011). The main feature that distinguishes ESV from the conventional singular vector approach is that the linear operator is derived empirically from a large number of hindcasts. Using matrix multiplication, the empirical linear operator is derived using many initial and final states as follows:

$$
\mathbf{L}=\mathbf{Y} \mathbf{X}^{\mathrm{T}}\left(\mathbf{X} \mathbf{X}^{\mathrm{T}}\right)^{-1}
$$

where each column of $\mathbf{X}$ and $\mathbf{Y}$ contains the state vectors of the hindcasts at the initial and final time, respectively.

In this study, the linear operator is obtained in a reduced space through a combined empirical orthogonal function (CEOF) analysis using equatorially averaged $\left(15^{\circ} \mathrm{S}-15^{\circ} \mathrm{N}\right) 850 \mathrm{hPa}, 200-\mathrm{hPa}$ zonal wind, and 200-hPa velocity potential initial condition and hindcast data during boreal winter (November-April) from 1990 to 1999. The total number of hindcasts used to obtain the linear operator is 1812 . To remove the interannual variability, the anomaly related to the MJO is calculated by subtracting the seasonal cycle and the previous 120-day mean (Wheeler and Hendon 2004; Rashid et al. 2011). Note that the 120-day-mean value for the $n$th day forecast is obtained by using $n$ days of forecast output and 120- $n$ days of observations. Then, the anomaly fields are normalized by the square root of the longitudinally $\left(0^{\circ}-360^{\circ} \mathrm{E}\right)$ averaged variance. $\mathrm{CEOFs}$ are computed

\footnotetext{
${ }^{2}$ This is in fact part of a larger suite of 6-month hindcasts, although for the purposes of this study we focus on the first 30 days of the hindcasts for the period 1990-99.
} 
from the history of initial state vectors [i.e., $\mathbf{X}$ in Eq. (1)], and only the first 5 leading modes are retained. Similarly, CEOFs are computed for the 10-day lead, dailyaveraged forecast data [Y in Eq. (1)], but in this case only the two leading CEOFs are retained. Therefore, the dimension of the linear operator $(\mathbf{L})$ is $2 \times 5$. Finally, we formulate a separate linear operator for each of the initial MJO's eight phases.

By retaining only the leading CEOFs in the linear operator we filter out modes that tend to be noisy and difficult to interpret, and thereby minimize statistical sampling issues and overfitting. While this is a rather strong filter, we note that the 5 leading CEOFs explain about $70 \%$ of $\mathrm{MJO}$ variability (i.e., the variability within the 20-90-day period). It is also not inconsistent with Wheeler and Hendon (2004), who show that the two dominant CEOFs explain about $60 \%$ of the total MJO variability (Wheeler and Hendon 2004). We acknowledge, however, that the number of modes that need to be retained to best represent the linear operator for seasonal prediction applications remains an open question (Kug et al. 2010, 2011).

One difference in our characterization of the MJO compared with Wheeler and Hendon (2004) is that we use 200-hPa velocity potential as a proxy for convection instead of outgoing longwave radiation (OLR). We do this primarily because the velocity potential field is more closely linked to the model's state variables than is OLR (since we need to initialize the state variables). This is important because OLR is a diagnostic quantity that is not assimilated, and so it is likely to be less accurate and suffer from larger bias than quantities more directly linked to the wind field. We also note that velocity potential is a commonly predicted variable for showing MJO propagation in many studies (Molinari et al. 1997; Waliser et al. 2003b; Tanaka et al. 2004; Waliser et al. 2006). The upper-level velocity potential of course cannot fully reflect the complex pattern of convection, especially when the convective activity related to the MJO passes over the Maritime Continent. We do, however, allow for some additional flexibility at the large scales (within the velocity potential representation) by formulating the linear operator to be a function of the phase of the MJO.

After obtaining the linear operator, we perform a singular-value decomposition (SVD) to obtain the singular vectors. The fastest growing singular vector (i.e., corresponding singular values are greater than one) is defined as the ESV mode (Kug et al. 2010, 2011). It was found that the largest singular value is greater than one for all initial MJO phases, indicating that the modes will grow when they are used as the initial perturbations. For example, the singular value is largest at MJO phase

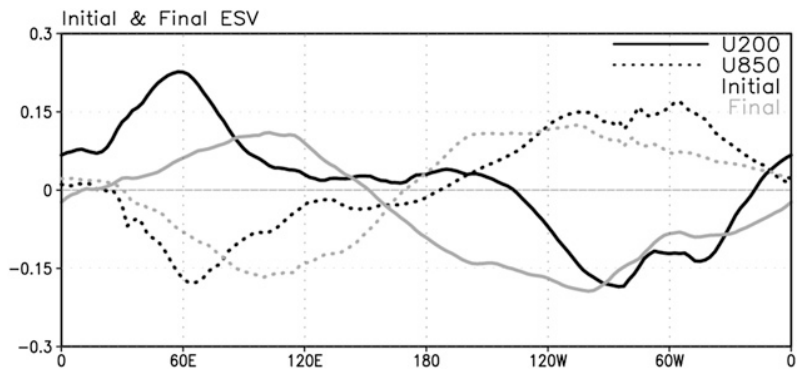

FIG. 1. The equatorially averaged $\left(15^{\circ} \mathrm{S}-15^{\circ} \mathrm{N}\right)$ initial (black lines) and final (gray lines) ESV of zonal wind at $200 \mathrm{hPa}$ (U200, solid line) and zonal wind at $850 \mathrm{hPa}$ (U850, dotted line) at MJO phase 4 . Note that the values are normalized.

4 with a value of 1.11 and lowest at MJO phase 2 with a value of 1.02. Hereafter, the left (right) singular vector with the largest singular value is denoted as the initial (final) ESV. Sensitivity tests with different forecast lengths (i.e., the ESV is computed using 5-, 10-, and 20 -day lead forecasts) show that the singular values generally increase as the forecast lead time is increased.

Because the time periods used to calculate the ESVs overlap with those used for the hindcasts, this methodology has not been fully tested as to whether it is applicable to an operational forecasting system. We have, however, done some cross validation, primarily to assess the stability of the ESV patterns. In particular, we have recomputed the ESVs for subsets of the data (by removing one year at a time) and found that the ESV structures are quite stable (not shown).

Figure 1 shows the initial and final ESVs for MJO phase 4. The initial ESV shows positive peaks in the 200-hPa zonal wind over the western Indian Ocean, while it shows negative peaks over South America. The initial ESV of the 850-hPa zonal wind shows a pattern opposite to that of the $200-\mathrm{hPa}$ zonal wind, which implies a baroclinic structure for the initial ESV. The final ESV shows a positive peak in the 200-hPa zonal wind over the Maritime Continent and a negative peak over the far-eastern Pacific. Similar to the initial $\mathrm{ESV}$, there is a clear baroclinic structure in the upperand low-level winds. It is interesting that the wind signals of the initial ESV over the Indian Ocean appear to have propagated to the east, and the wind signals of final ESV are over the maritime continents. This eastwardpropagating feature of the ESV is consistent with the characteristics of optimal initial perturbations found in previous studies using the breeding method (Chikamoto et al. 2007). Sensitivity tests with different forecast output show that the ESV using a 5-day lead forecast produces a zonal phase difference between the initial and final ESV that is almost zero because of the short forecast lead time. Also, the final ESV based on a 20-day 

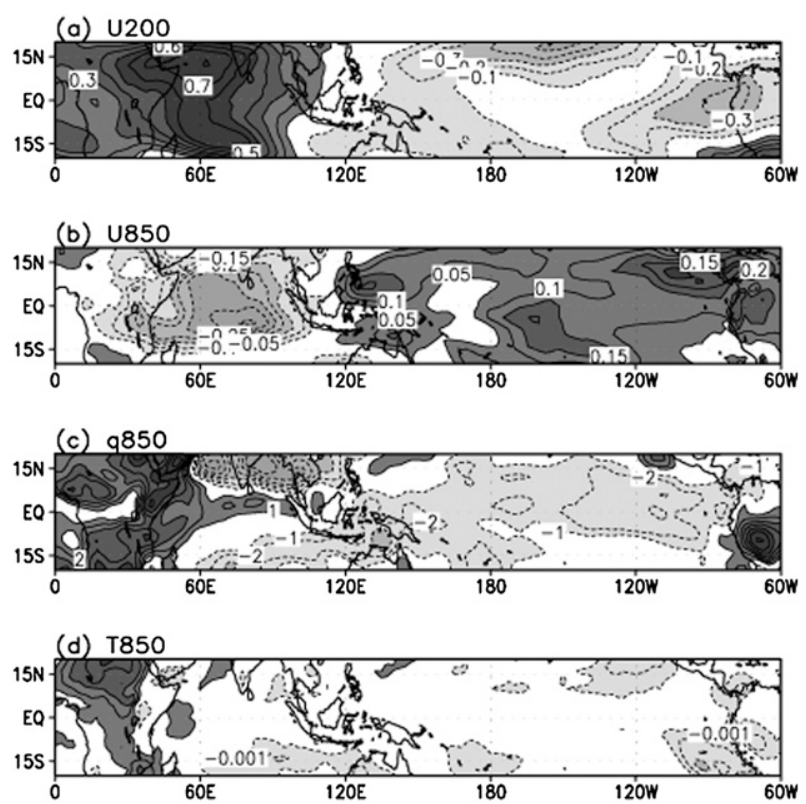

FIG. 2. The spatial pattern of initial ESV of (a) 200-hPa zonal wind (U200), (b) 850-hPa zonal wind (U850), (c) 850-hPa specific humidity (q850), and (d) 850-hPa air temperature (T850) at MJO phase 4 . The units of zonal winds, specific humidity, and air temperature are $\mathrm{m} \mathrm{s}^{-1}, 10^{5} \mathrm{~g} / \mathrm{kg}$, and ${ }^{\circ} \mathrm{C}$, respectively.

lead forecast time shows a zonal wavenumber-2 structure, which is also dominant at 20-day lead forecasts in the CNTL predictions (see CNTL in Fig. 12d).

In addition to the ESV pattern for U200, U850, and VP200, the related patterns for all prognostic variables are obtained using linear regression to generate initial perturbations that are well balanced among all prognostic variables. That is, we construct the regressed patterns of other variables related to the five dominant CEOFs, where the predictors are the associated principle components (PCs). After the ESV is obtained, the spatial pattern of initial perturbations for other variables is calculated by multiplying each ESV magnitude by the regressed patterns. Figure 2 shows the spatial pattern of the initial ESV for the regressed zonal winds, specific humidity, and temperature at MJO phase 4. Consistent with Fig. 1, the upper- and lower-level zonal winds have anomalies over the equatorial Indian Ocean and the far-eastern Pacific. In addition, there are strong negative anomalies of the $200-\mathrm{hPa}$ zonal wind over the off-equatorial central Pacific. The ESV anomalies in circulation appear to be dynamically linked to the moisture fields in that, over the far-western Indian Ocean, there is positive moisture anomaly where there is low-level convergence. Also, there is a positive temperature anomaly over Africa possibly generated by zonal warm advection because of the easterly wind anomalies.

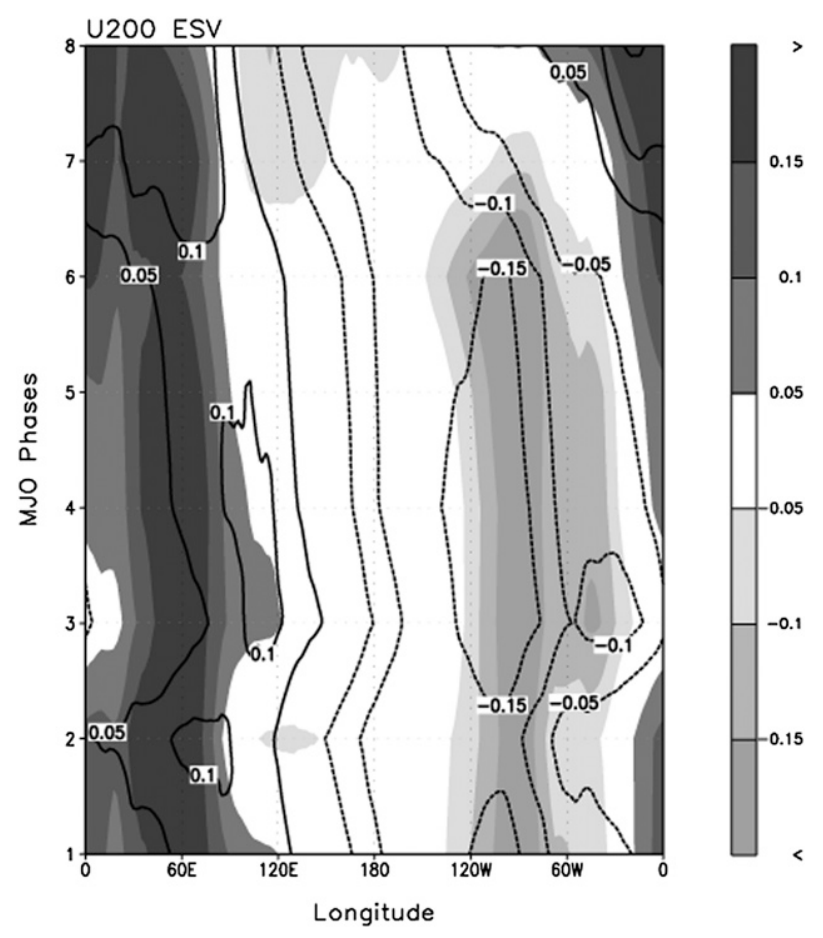

FIG. 3. The equatorially averaged $\left(15^{\circ} \mathrm{S}-15^{\circ} \mathrm{N}\right)$ initial (shading) and final (contour) ESV of $200-\mathrm{hPa}$ zonal wind with respect to MJO phases. Note that the values are normalized.

These results suggest that the linear regression successfully captures the dynamical linkages between the variables.

Figure 3 shows the equatorially averaged $\left(15^{\circ} \mathrm{S}-15^{\circ} \mathrm{N}\right)$ ESVs of the $200 \mathrm{hPa}$ zonal wind for all MJO phases. The initial ESVs for all MJO phases show robust anomalies over the Indian Ocean and South America, while the ESVs at MJO phase 7 and 8 shows negative anomalies over the Maritime Continent. This shows that the spatial pattern of the ESVs is not sensitive to the phase of the MJO. The location of the maximum positive values of the upper-level wind in the final ESVs (near $110^{\circ} \mathrm{E}$ for phases 3-5) is indicative of eastward propagation from the Indian Ocean to the Maritime Continent. The longitudinal location of the negative anomalies of the final ESVs is similar to that of initial ESVs, or shifted westward slightly, indicating that the eastward propagating signal is limited to the Indian Ocean where the MJO appears to initiate.

After obtaining the spatial pattern of the initial perturbations for all variables, the magnitude of the perturbation needs to be defined. While this is somewhat arbitrary, we define the magnitude of the initial ESV based on the $200 \mathrm{hPa}$ zonal wind. In particular, the root-mean-square (RMS) magnitude of the equatorially-averaged initial ESV over the globe is set to 
$10 \%$ of the RMS of the equatorially-averaged and filtered (20-90 days) $200 \mathrm{hPa}$ zonal wind anomaly over the globe. The filter consists of a LANCZOS bandpass filter (using 45 weights; Duchon 1979), and is applied to the daily-mean zonal-wind anomalies at $200 \mathrm{hPa}$. The magnitudes of the initial perturbations of the all variables are obtained in the same way.

\section{Results}

\section{a. Experimental design for MJO forecasts}

Here we take advantage of a number of existing GEOS-5 CGCM hindcasts to form our baseline set of experiments. We focus in particular on a set of 30-day hindcasts initialized for the 10 winters (NovemberApril) of 1990-99 with an interval of 10 days between the predictions. That is, the model predictions are made every 10 days from 1 November to 30 April, to produce a total of 180 forecasts. The 10-day intervals were chosen to minimize the impact of any correlations between the starting dates.

Two sets of predictions were generated, denoted hereafter by ESV and CNTL. The ESV predictions consist of two ensemble members whose initial states are obtained by adding and subtracting the ESV to the baseline initial conditions (i.e., the initial states obtained from the replay approach described earlier). The skill of the ESV-based predictions is compared with the skill of a set of CNTL predictions using random perturbations. To generate random perturbations, we utilized the regressed patterns of the various prognostic fields (described earlier) associated with the five dominant CEOFs. The weighting of each CEOF (the PC) is chosen to be a random number with a uniform distribution between -1 and 1 . The initial perturbations for all variables are then obtained by multiplying these random numbers and the regressed patterns to produce what appear to be dynamical balanced perturbations. Just as for the ESV, the magnitude of the random perturbation is scaled to be $10 \%$ of the root-mean-square (RMS) magnitude of the equatorially averaged and filtered (20-90 days) 200-hPa zonal wind anomaly over the globe.

We note that the time-averaged equatorial-mean spread (standard deviation) of the control predictions with random perturbation is about $65 \%$ of the spread of ESV predictions. That is to be expected in view of the relatively fast-growing nature of the ESV perturbations, but it nevertheless indicates that the spread of the random perturbation is reasonable and that the control predictions provide a useful benchmark for assessing the ESV predictions.

We generated seven sets of predictions with random perturbations. These, together with the unperturbed
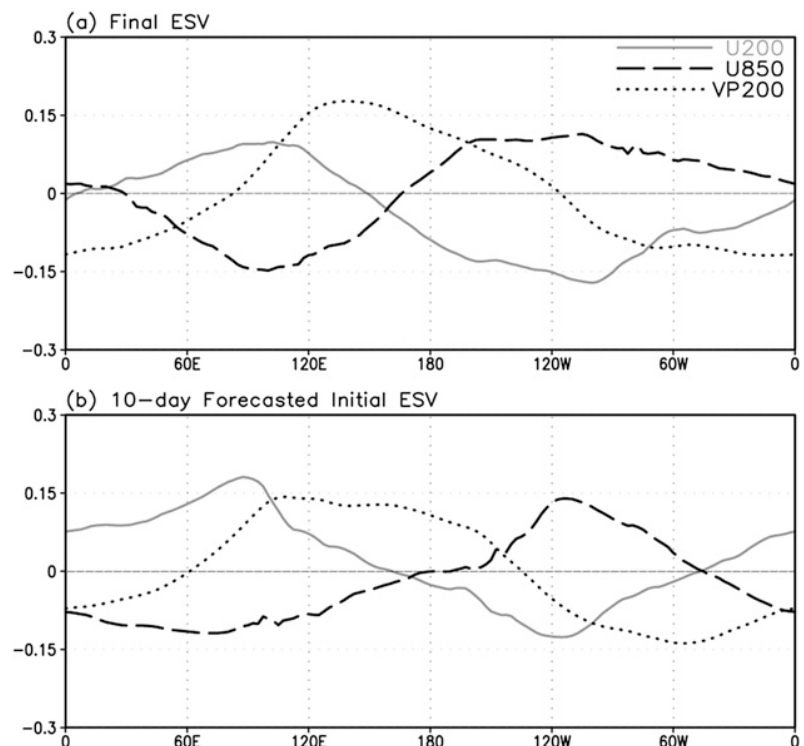

FIG. 4. (a) The MJO phase-averaged final ESV and (b) CEOFfiltered 10-day-forecasted initial ESV for all hindcast cases. The spatial pattern of ESV after 10-day lead forecast is calculated by the averaged difference between the 10-day lead forecast without any perturbation and that with positive ESV using the entire hindcast samples. Note that the values are normalized.

predictions allow for 28 combinations of two members with which to compare the 2 -member ensembles of the ESV predictions. For the 28 possible combinations of the CNTL predictions, the approximate upper $95 \%$, and $99 \%$ confidence levels of the correlations are defined as second largest and largest values, respectively. Similarly, the lower 95\% and 99\% confidence levels are defined as the second lowest and lowest values, respectively. Note that the CNTL prediction skill is defined as the mean correlation of the 28 samples.

\section{b. MJO forecast results}

We begin by examining how well the linear operator captures the evolution of the initial ESVs in the nonlinear integration. To do so, the final ESV that evolved using the linear operator is compared with the 10-day integration of the initial ESV using the CGCM. The spatial pattern of the ESV after 10 days is calculated by the averaged difference between the 10-day lead forecast with a positive ESV and that without any perturbation using the entire hindcast sample, then the difference is CEOF-filtered using 2 dominant modes. Note that we also used 2 dominant CEOF modes to obtain final ESV. Figure 4 shows the final ESV and the CEOF-filtered 10-day forecast of the initial ESV using the CGCM. Note that final ESV shown in this figure is averaged over all $\mathrm{MJO}$ phases because the spatial pattern of ESVs is not sensitive to the MJO phases. In 
(a) CNTL

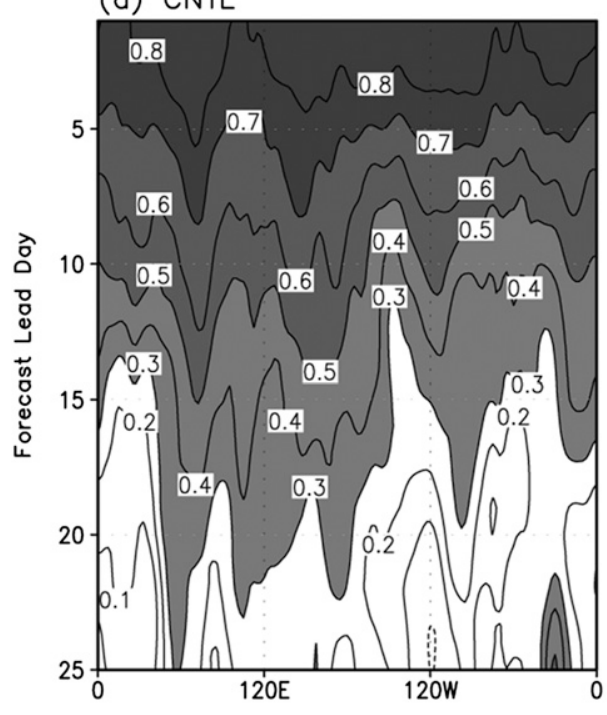

(b) ESV

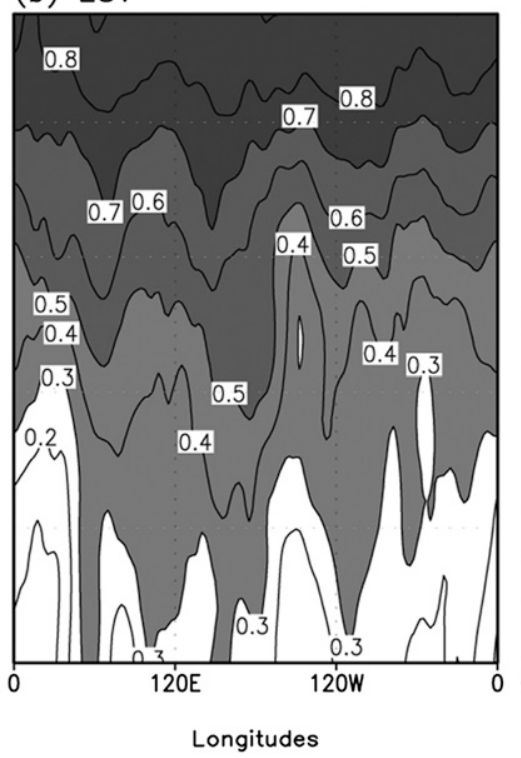

(c) ESV-CNTL

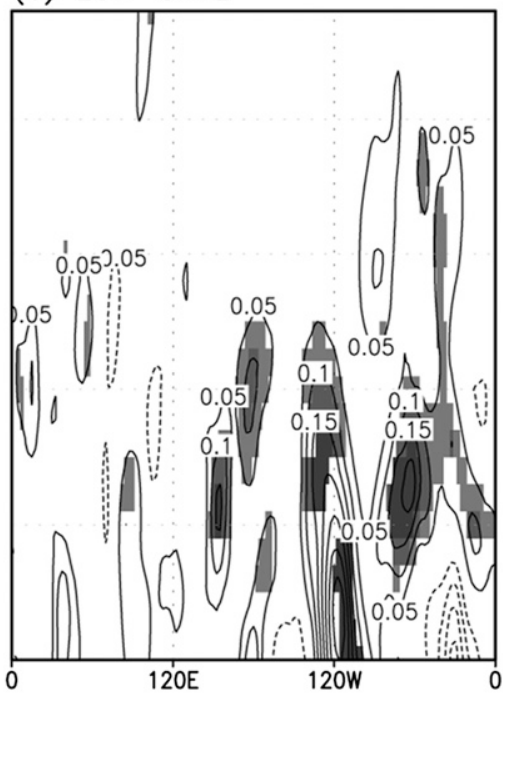

FIG. 5. The correlation skill of the equatorially averaged $\left(15^{\circ} \mathrm{S}-15^{\circ} \mathrm{N}\right) 200$-hPa zonal wind in the (a) CNTL and (b) ESV prediction. (c) The difference in the correlation skill between the ESV predictions and the CNTL predictions with $99 \%$ confidence level are shown. Note that the mean correlation of 28 samples of CNTL predictions is shown as CNTL prediction.

the final ESV, the positive (negative) zonal wind anomaly at $200 \mathrm{hPa}$ over the Maritime Continent (South America) is clearly shown. Consistent with the spatial pattern of upper-level zonal wind, there is upper-level convergence over the western-central Pacific. This feature is well captured in the forecasted initial ESV using the CGCM. For example, the forecasted initial ESV also shows a positive (negative) zonal wind anomaly at $200 \mathrm{hPa}$ $(850 \mathrm{hPa})$ over the Maritime Continent, even though the peaks of anomalies are shifted to the west. In addition, the positive peak of velocity potential at $200 \mathrm{hPa}$ over the western-central Pacific is also shown both in the final ESV and the forecasted initial ESV. This indicates that the evolution of the perturbation, calculated from the empirical linear operator, captures to some extent the evolution of the initial perturbation in the nonlinear model.

To evaluate the impact of the ESV on the MJO forecast skill, the skill is compared with that of the CNTL predictions. Figure 5 shows the correlation skill of the unfiltered equatorial zonal wind at $200 \mathrm{hPa}$ from the CNTL and ESV predictions. Note that the mean correlation of the 28 samples of the CNTL predictions is shown as CNTL prediction. In the CNTL predictions, the correlation skill of the unfiltered zonal wind at $200 \mathrm{hPa}$ drops below 0.5 after 12 days. After 20 days, the correlation skill drops below 0.2 over most regions. For the ESV predictions, the correlation skill show some significant improvements compared with the CNTL after 10-day lead times over the central-eastern Pacific.
We next turn to the forecast skill of the dominant CEOF-related fields. In this case (before computing the correlations), both the predicted and observed zonal wind anomalies at $200 \mathrm{hPa}$ are spatially filtered to retain only the contributions from the five dominant observed CEOFs. Figure 6 shows the correlation skill of the CEOF-filtered equatorial zonal wind at $200 \mathrm{hPa}$. In the CNTL predictions, the correlation skill drops below 0.5 after 15 days. In particular, the correlation skill over the eastern Pacific reaches 0.3 after 8 days, which indicates that the correlation skill over the eastern Pacific is a local minimum compared to the other regions. On the other hand, for the ESV predictions, the correlation skill over the eastern Pacific does not reach 0.3 until about 12 days. Also, the correlation skill over the Maritime Continent falls to 0.3 after 20 days in the ESV prediction, while in the CNTL prediction the correlations is already below 0.2 at that forecast lead time. The difference in the correlation skill (Fig. 6c) shows that the correlation improvement is largest over the eastern Pacific and Maritime Continent with 99\% confidence level.

Figure 7 shows the correlation skill of a bivariate index (Kang and Kim 2010; Rashid et al. 2011) along with confidence levels computed from the 28 different control predictions. The value of bivariate correlation skill for the CNTL prediction drops to 0.5 at 16 days. Note that this prediction skill is higher than the autoregressive model introduced in Rashid et al. (2011), and it is similar to the prediction skill of the POAMA model with single 
(a) CNTL

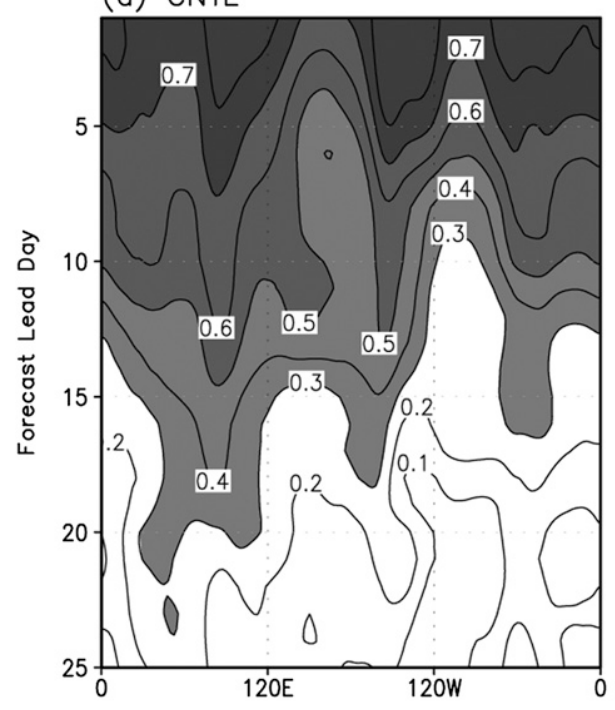

(b) ESV

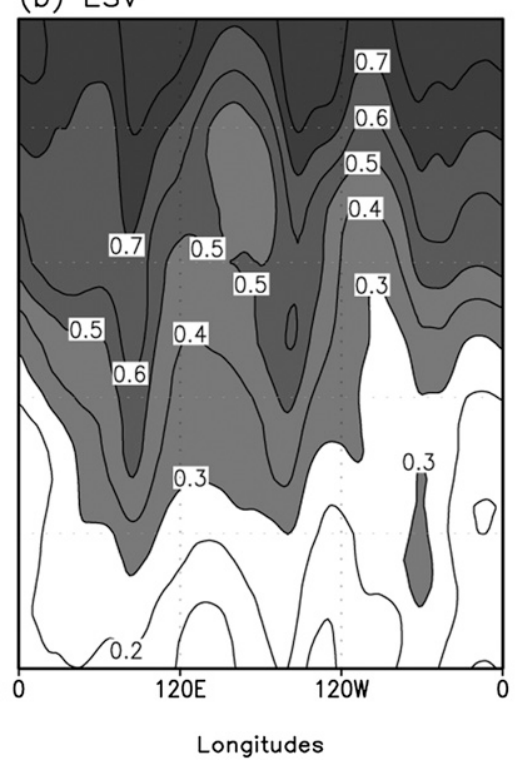

(c) ESV-CNTL

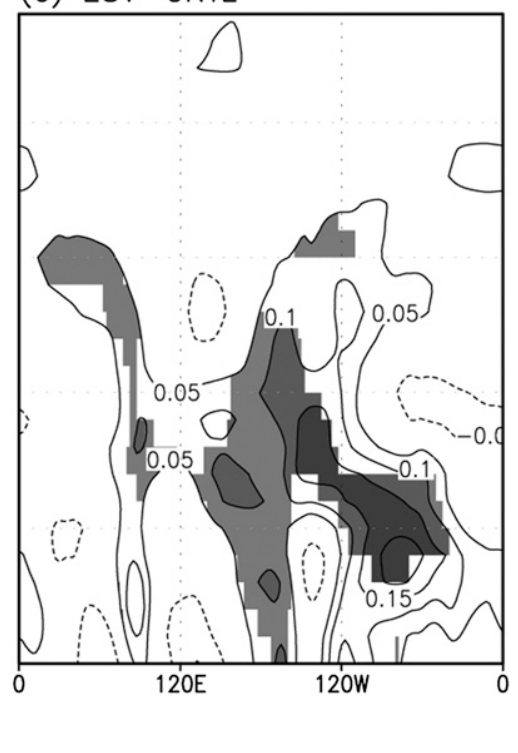

FIG. 6. As in Fig. 5, but the anomaly is CEOF filtered. Note that five dominant CEOFs are used.

ensemble member. In the ESV prediction, it is clear that there is systematic improvement in predicting the bivariate index, showing that the bivariate correlation in ESV prediction is above 0.5 out to a lead time of 17 days. The improvement in the correlation at 15 days is 0.05 with a $99 \%$ confidence level, implying that the ensemble prediction with the ESV is beneficial to MJO prediction.

The correlation skill of the RMM1 and RMM2 indices is shown in Fig. 8. It is found that the skill improvement of the RMM2 index is slightly larger than that of RMM1 index. The correlation coefficient of the RMM2 index in the ESV prediction is about 0.5 at 20 days, while the correlation of RMM2 index is 0.5 at 14 days. On the other hand, the correlation skill of the RMM1 index in both the ESV and CNTL predictions reaches 0.5 at day 17 .

A number of studies have examined the sensitivity of MJO forecast skill to the MJO amplitude (Jiang et al. 2008; Kang and Kim 2010; Rashid et al. 2011). Figure 9 shows, for example, the correlation skill of the bivariate index with respect to the initial MJO amplitude. Here, that the MJO amplitude is defined as $\sqrt{a_{1}(0)^{2}+a_{2}(0)^{2}}$, where, $a_{1}(0)$ and $a_{2}(0)$ are the observed (i.e., MERRA) RMM1 and RMM2 at the initial time. We divided the total cases into two groups, one consists of the strong MJO cases when the initial MJO amplitude is larger than one, and the other consists of the weak MJO cases, when the initial MJO amplitude is smaller than one. In the CNTL prediction, the correlation skill of the bivariate index for the strong MJO case is higher than that for the weak MJO case during the early period of the forecast. For example, the correlation skill for the strong MJO case is more than 0.8 , while that for the weak MJO cases it is less than 0.7 at 5-day lead time. However, the correlation skill with respect to the MJO amplitude becomes similar after 15 days in the CNTL predictions. In the ESV predictions, the correlation at 15 days for the weak and strong MJO cases is about 0.55 and 0.5 , respectively.

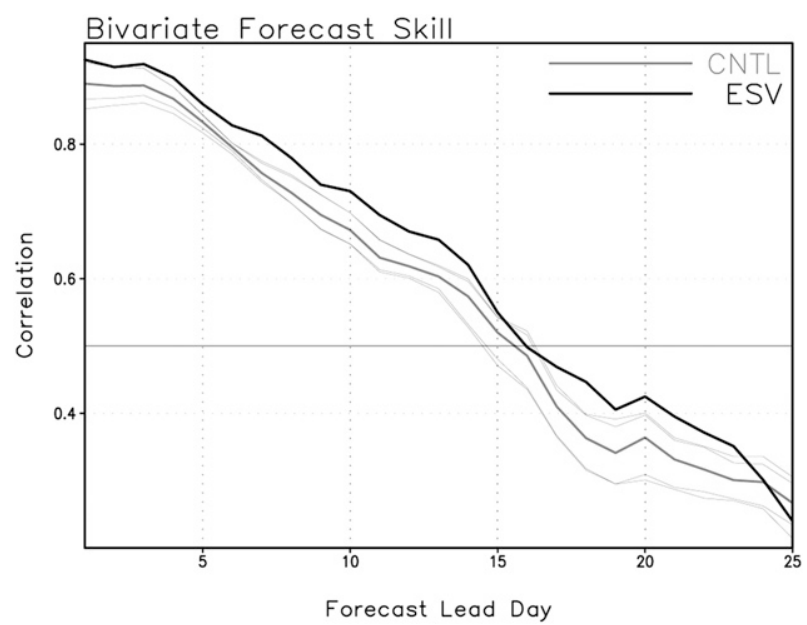

FIG. 7. (a) The bivariate correlation skill of the CNTL (gray line) and ESV (black line) predictions for all hindcast cases. The thin gray line denotes $95 \%$, and $99 \%$ confidence level using samples of CNTL prediction results with different combination of random and no perturbations. 
(a) RMM1

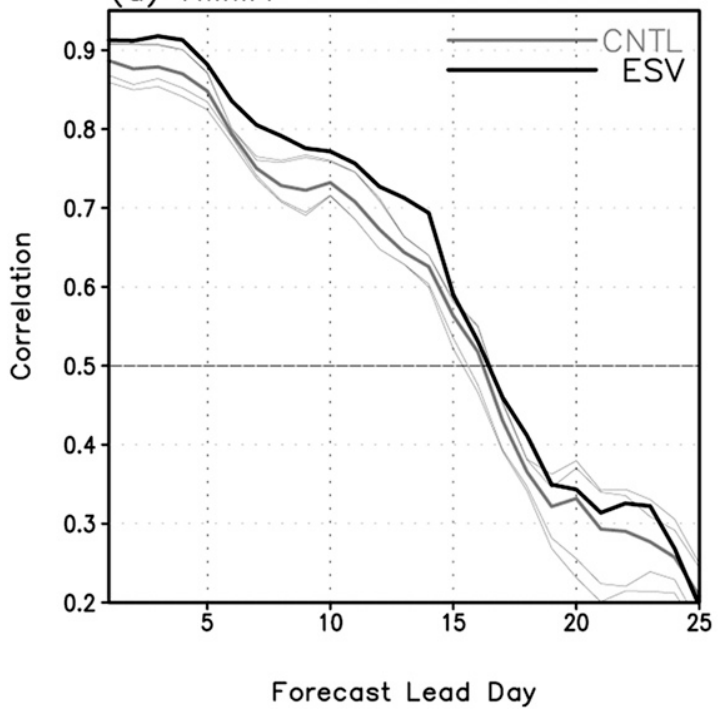

(b) RMM2

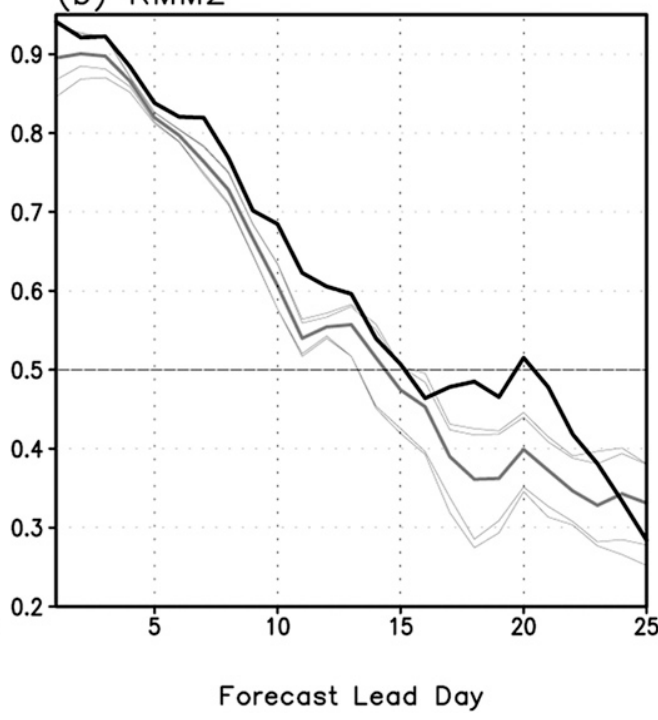

FIG. 8. The correlation skill of (a) RMM1 and (b) RMM2 index in the CNTL (gray) and ESV (black) predictions for all hindcast cases are shown. The thin gray line denotes $95 \%$, and $99 \%$ confidence level using samples of CNTL prediction results with different combination of random and no perturbations.

The correlation skill improvement in the ESV predictions is much higher for the weak MJO case than that for the strong MJO case. For the strong MJO case, the forecast lead day at which point the correlation skill drops to 0.5 is about the same for the CNTL and ESV predictions, while for the weak MJO case, it is about 4 days longer in the ESV prediction. This shows that the ESV is especially beneficial in the weak MJO cases and suggests that the fast-growing perturbations are more effective for the less predictable periods when the forecast skill is sensitive to the uncertainty in the initial conditions. This is consistent with previous results based on fast-growing perturbations determined from both breeding and the singular-vector approach (Chen et al. 1997; Xue et al. 1997a,b; Cai et al. 2003; Ham et al. 2009; Kug et al. 2010).

Figure 10 shows the bivariate correlation skill in the CNTL and ESV predictions as a function of the phase of the MJO. In the CNTL prediction, the correlation skill is highest during MJO phases 5-8. For example, the correlation skill drops to 0.5 by about day 12 during phases $1-$ 4 , while during phases $5-8$, the correlation remains above 0.5 until day 17. At forecast lead times longer than 20 days, the CNTL correlation skill is lowest in MJO phases 3-7, while for the ESV predictions, the correlation skill shows significant improvements for those phases. The improvement of the correlation skill is largest for the MJO phase 4 , exceeding 0.25 between lead times between 20 and 25 days.

The spatial distribution of the skill improvements are highlighted in Fig. 11 in terms of the RMS error (RMSE) between the CEOF-filtered equatorial velocity potential at $200 \mathrm{hPa}$ in the prediction experiments and the observations for the cases when the initial MJO phase is 4 . In the CNTL predictions, the RMSE is relatively high over the Indian Ocean, western Pacific, and Atlantic Ocean beyond a forecast lead of 10 days. The RMSE grows

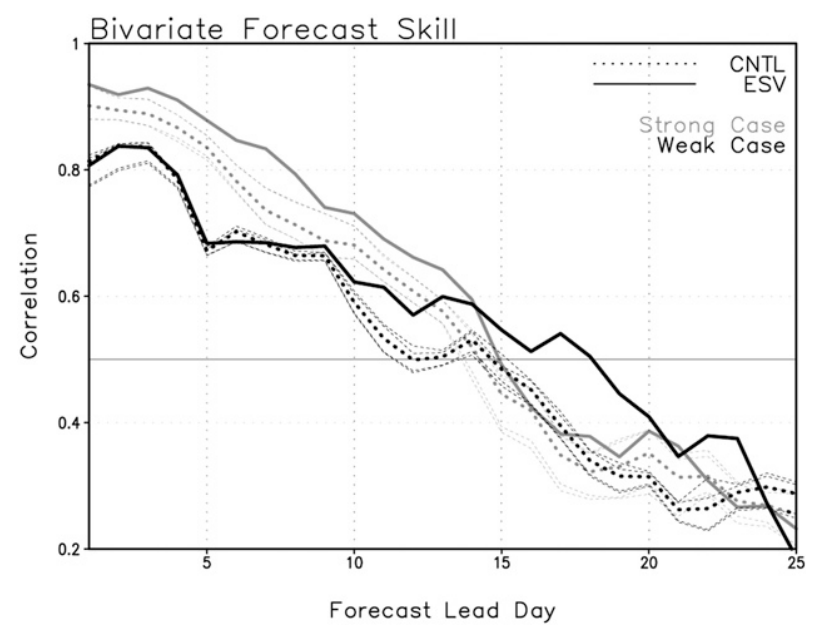

FIG. 9. The bivariate correlation skill of the CNTL (dotted line) and ESV (solid line) predictions for the strong (gray) and weak (black) MJO cases are shown. The MJO amplitude is defined as the square root of the RMM1 plus RMM2 variance at the initial time. The strong (weak) MJO case when initial MJO amplitude is larger (smaller) than one. The thin line denotes $95 \%$ and $99 \%$ confidence level using samples of CNTL prediction results with different combination of random and no perturbations. 
(a) CNTL

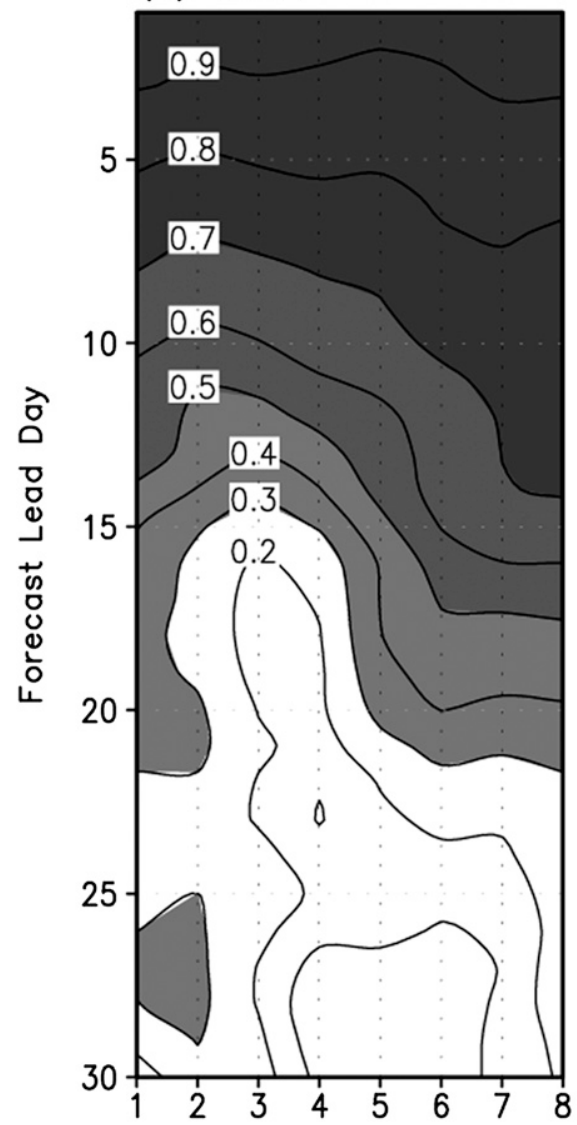

(b) ESV

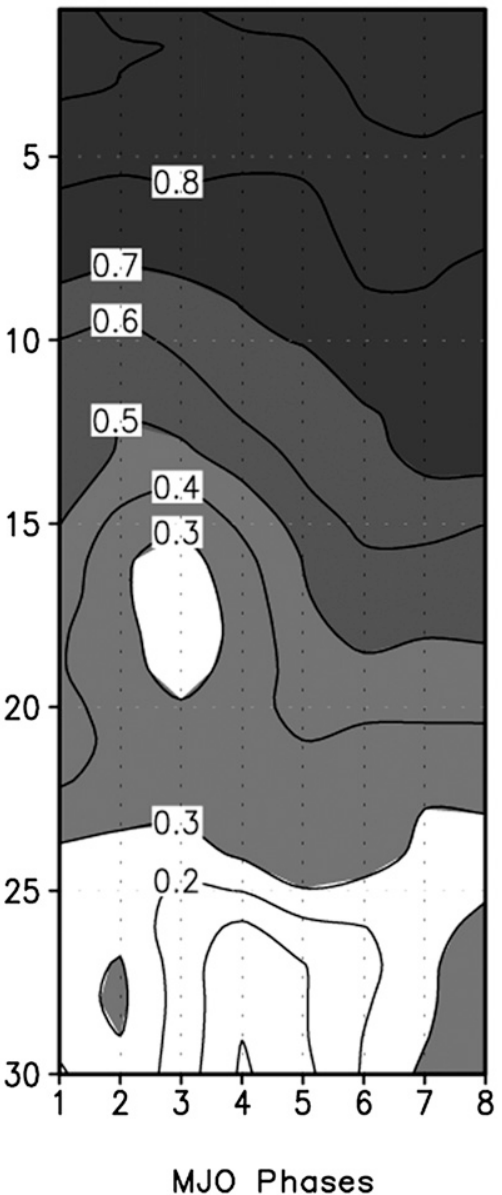

(c) ESV-CNTL

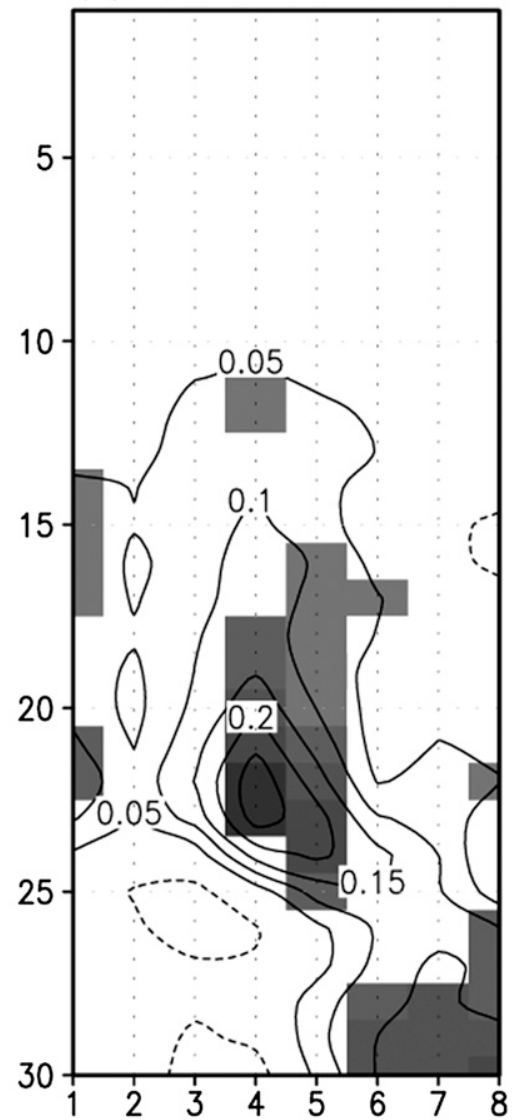

FIG. 10. The bivariate correlation skill of (a) CNTL and (b) ESV prediction with respect to the initial MJO phases. (c) The difference of the correlation skill in the ESV prediction from that in the CNTL prediction is shown. The $x$ axis ( $y$ axis) denotes the MJO phases (forecast lead day). Note that the improvement over the $99 \%$ confidence level is only shaded in (c).

to a value of about 1.4 over these regions in the CNTL prediction, indicating a climatological forecast (Rashid et al. 2011). However, compared to the CNTL prediction, there is systematic reduction of the RMSE in the ESV prediction. For example, the RMSE in the ESV predictions during lead times of $5-15$ days is less than 0.6 over the Atlantic Ocean, while that in the CNTL prediction is more than 0.7. In addition, the RMSE over the Indian Ocean is less than 1.4 during the entire forecast period with the ESV, indicating that the MJO forecast skill of the ESV-based predictions is better than a climatological forecast out to 30 days. Note that the RMSE reduction beyond 15-day lead times is primarily over those regions where the RMSE is a local maximum. For example, the reduction of the RMSE is greater than 0.4 during 20 25-day forecast lead times over the Indian ocean.

To investigate the time evolution of MJO fields in the prediction experiments, Fig. 12 shows the composite of the
CEOF-filtered 200-hPa velocity potential anomalyagain for the case where the MJO is initially in phase 4 . In the observations (i.e., MERRA reanalysis), the negative (positive) $200-\mathrm{hPa}$ velocity potential anomaly is robust over the Indo-Maritime Continent (far-eastern Pacific) during 1-5-day lead times. The observed divergence signal moves to the east, and the negative value of upper-level velocity potential (i.e., upper-level divergence) anomaly propagates from the Maritime Continent at lead times of 1-5 days to the far-eastern Pacific at lead times of 2125 days. As the signal moves to the east, the magnitude of MJO-related anomaly gradually weakens.

During the early phase of the forecast, the spatial pattern of the MJO-related anomaly is similar to the observed in both prediction experiments. However, in the CNTL prediction, the eastward propagation of the velocity potential anomaly is too weak, while the observed peak propagates to the east. In addition, zonal 
(a) CNTL

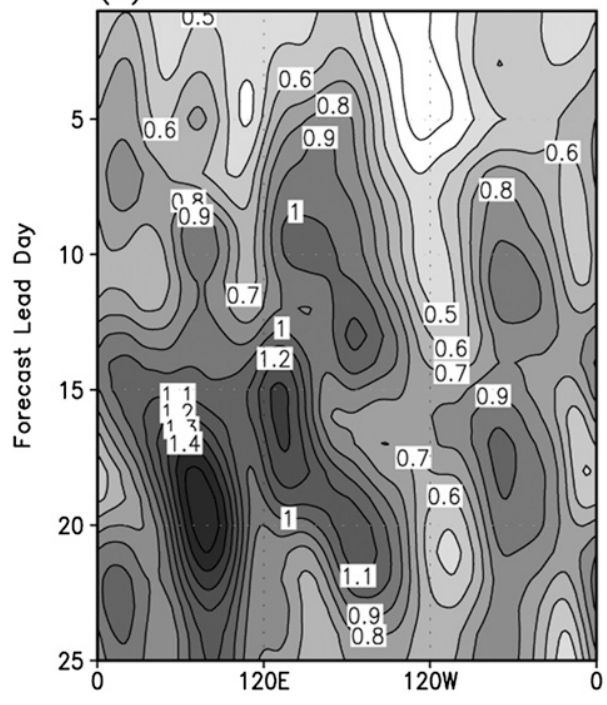

(b) ESV

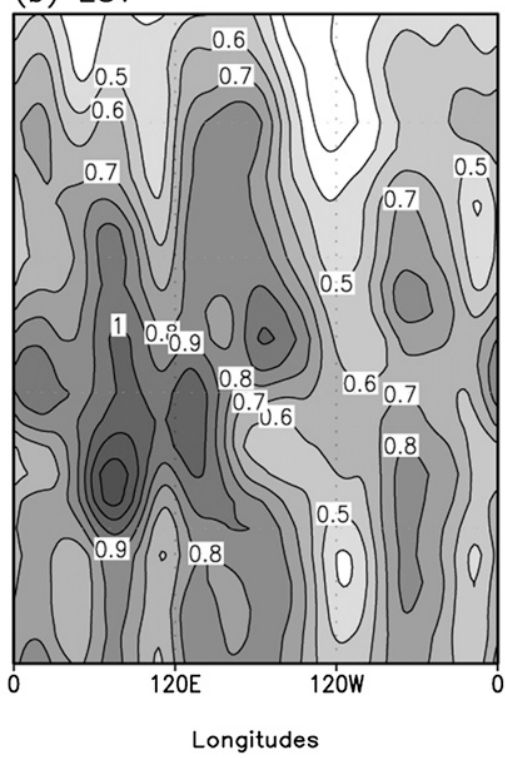

(c) CNTL-ESV

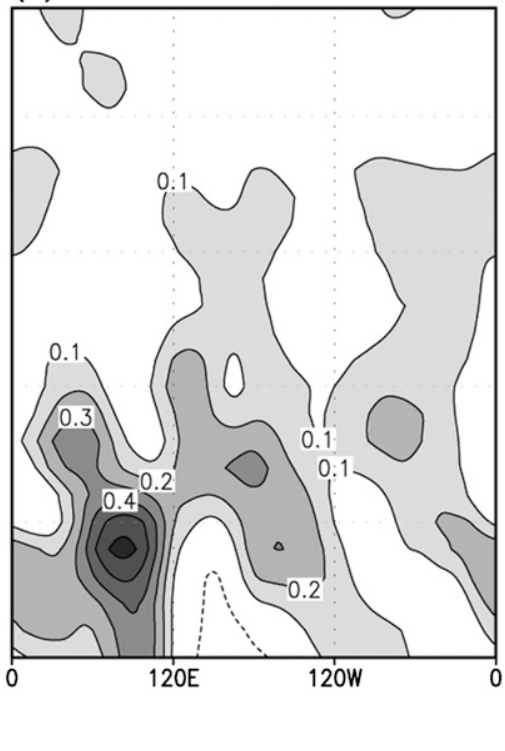

FIG. 11. The RMSE of the 200-hPa velocity potential at initial MJO phase 4 in the (a) CNTL and (b) ESV prediction. (c) The difference of the RMSE in the CNTL prediction from that in the ESV prediction is shown in panel.

wavenumber-1 structure is damped out too quickly. For example, during 11-15-day lead forecast in CNTL prediction, there are two positive and negative peaks of the velocity potential over the equatorial regions. On the other hand, in the ESV prediction, the wavenumber-1 structure is somewhat dominant until days 16-20. Being consistent with Fig. 11, the positive (negative) velocity potential anomaly over the Indian Ocean (far eastern Pacific) after an 11-day lead forecast is also simulated better in the ESV prediction.

\section{Summary and discussions}

This study investigated the impact on forecast skill of optimal initial perturbations based on empirical singular vectors (ESVs), with a focus on the MJO during the boreal winter season. The ESV approach employs a reducedspace, linear approximation to the full nonlinear GEOS-5 CGCM, computed from the statistics of a 10-yr (1990-99) hindcast dataset. It was found that the eastward evolution (over the Maritime Continent) of the ESV over the first 10 days of the forecasts resembles aspects of the MJO and replicates the evolution produced in the fully nonlinear model integrations.

ESV-based predictions were carried out with two ensemble members ( \pm the ESV perturbation) for boreal winter season from 1990 to 1999 . The forecast skill was compared to that of a control (CNTL) set of predictions in which the two-member ensemble means are based on predictions with random perturbations. It was shown that the prediction experiment with the ESV has a systematically higher bivariate correlation skill compared to that with the random perturbations. In particular, the improvement of the correlation skill in the ESV prediction is greatest during the MJO phases $4-8$, characterized by enhanced convective activity over the Maritime Continent or western Pacific. During these phases the correlation skill in the CNTL prediction is lower than during the other MJO phases, indicating that the ESV perturbation approach is most effective during periods of low skill. Also, the improvement of bivariate correlation skill with the ESV is largest for weak MJO cases, when the skill improvement is considerably lower than for strong MJO cases.

While the approach used here provides information about the spatial pattern of the optimal initial perturbation, the magnitude of the initial perturbation is not well constrained. In fact, the selection of the amplitude of the ESV is somewhat arbitrary and is analogous to the need to select a norm magnitude in the breeding approach (Toth and Kalnay 1993; Ham et al. 2012). In this study, the magnitude of the ESV is determined as some fraction of the natural variability, however, further work is needed to determine whether there is an optimal magnitude for the initial perturbations.

Even though we focused here on the single fastestgrowing ESV, the number of available ESV modes is equal to the number of state vectors, so that in general, one can obtain multiple ESV perturbations. This is unlike the breeding approach, which is designed to 
OBS(MERRA): Phase 4

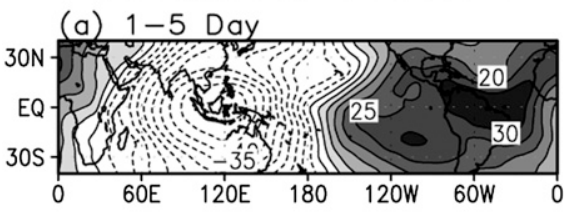

CNTL

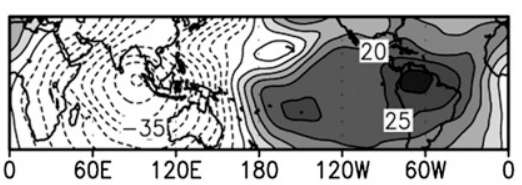

ESV

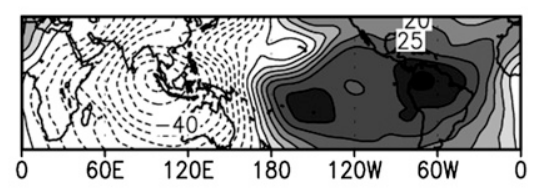

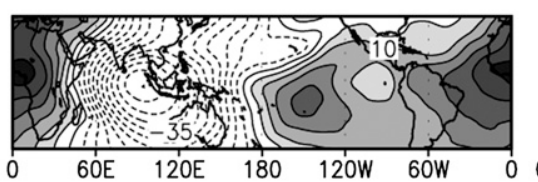
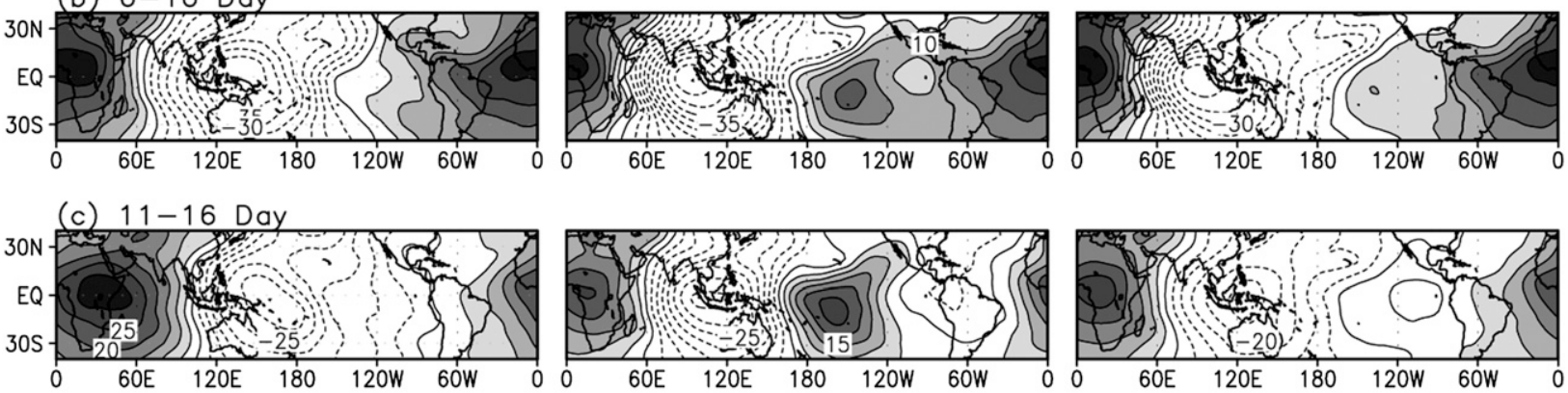

(d) $16-20$ Day
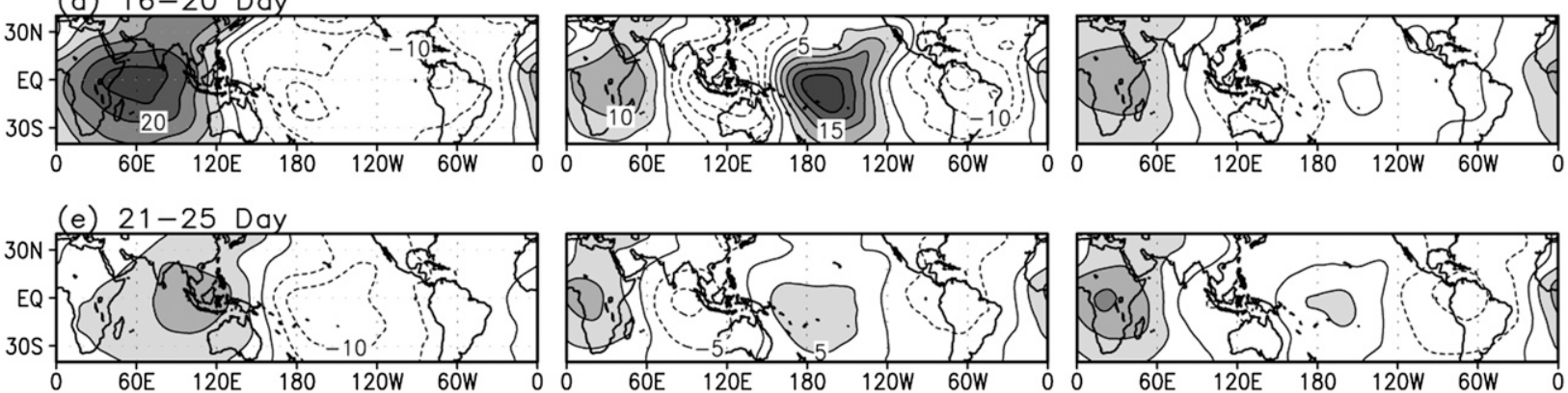

FIG. 12. The composite of 200-hPa velocity potential at initial MJO phase 4 in (left) the observations (i.e., MERRA), (middle) CNTL prediction, and (right) ESV prediction with respect to the forecast lead days.

generate a single fastest-growing perturbation. Further work is needed, however, to investigate the benefits of additional ESV perturbations.

There is little question that an ensemble approach is essential to producing skillful predictions of the MJO with dynamical models. Progress in identifying optimal perturbations for subseasonal time scales has been slow at least in part because of the expense of running CGCMs with a large number of different initial conditions. This study shows that the ESV approach is a viable option for generating initial perturbations that reduce uncertainty in MJO predictions with a relatively small number of ensemble members. However, it is very likely that major advances in dynamically based predictions of the MJO will require a dual approach that addresses both perturbation strategies and model deficiencies in simulating the MJO.

Acknowledgments. Support for this project was provided by the NOAA Modeling, Analysis, Predictions, and Projections (MAPP) program and the NASA Modeling, Analysis and Prediction (MAP) program.

\section{REFERENCES}

Behringer, D. W., and Y. Xue, 2004: Evaluation of the global ocean data assimilation system at NCEP: The Pacific Ocean. Preprints, Eighth Symp. on Integrated Observing and Assimilation Systems for Atmosphere, Ocean and Land Surface, Seattle, WA, Amer. Meteor. Soc., 11-15. [Available online at http://ams.confex.com/ams/84Annual/webprogram/Paper 70720.html.]

Bergman, J. W., H. H. Hendon, and K. M. Weickmann, 2001: Intraseasonal air-sea interactions at the onset of El Niño. J. Climate, 14, 1702-1719.

Bloom, S., L. Takacs, A. DaSilva, and D. Ledvina, 1996: Data assimilation using incremental analysis updates. Mon. Wea. Rev., 124, 1256-1271.

Cai, M., E. Kalnay, and Z. Toth, 2003: Bred vectors of the ZebiakCane model and their potential application to ENSO predictions. J. Climate, 16, 40-56.

Carton, J. A., and B. S. Giese, 2008: A reanalysis of ocean climate Using Simple Ocean Data Assimilation (SODA). Mon. Wea. Rev., 136, 2999-3017.

Chen, Y.-Q., D. S. Battisti, T. N. Palmer, J. Barsugli, and E. S. Sarachik, 1997: A study of the predictability of tropical Pacific SST in a coupled atmosphere-ocean model using singular vector analysis: The role of the annual cycle and the ENSO cycle. Mon. Wea. Rev., 125, 831-845. 
Chikamoto, Y., H. Mukougawa, T. Kubota, H. Sato, A. Ito, and S. Maeda, 2007: Evidence of growing bred vector associated with the tropical intraseasonal oscillation. Geophys. Res. Lett., 34, L04806, doi:10.1029/2006GL028450.

Duchon, C., 1979: Lanczos filtering in one and two dimensions. J. Appl. Meteor., 18, 1016-1022.

Garcia, R. R., and B. A. Boville, 1994: "Downward control" of the mean meridional circulation and temperature distribution of the polar winter stratosphere. J. Atmos. Sci., 51, 2238-2245.

Griffies, S. M., M. J. Harrison, R. C. Pacanowski, and A. Rosati, 2004: A technical guide to MOM4 GFDL. NOAA/Geophysical Fluid Dynamics Laboratory Ocean Group Tech. Rep. 5, 32 pp. [Available online at http://data1.gfdl.noaa.gov/ arl/pubrel/r/ mom4p1/src/mom4p1/doc/mom4p1_synopsis.pdf.]

Ham, Y.-G., and I.-S. Kang, 2010: Growing-error correction of ensemble Kalman filter using empirical singular vector. Quart. J. Roy. Meteor. Soc., 136, 2051-2060, doi:10.1002/qj.711.

_ for El Niño ensemble prediction with Ensemble Kalman Filter. Climate Dyn., 33, 959-973, doi:10.1007/s00382-009-0582-z.

_- I.-S. Kang, and J.-S. Kug, 2012: Detection of two independent coupled bred vectors in the tropical Pacific and their application to ENSO prediction. Prog. Oceanogr., in press.

Hoffman, R. N., and E. Kalnay, 1983: Lagged averaged forecasting, an alternative to Monte Carlo forecasting. Tellus, 35A, 100-118.

Jiang, X., D. E. Waliser, M. C. Wheeler, C. Jones, M.-I. Lee, and S. Schubert, 2008: Assessing the skill of an all-season statistical forecast model for the Madden-Julian oscillation. Mon. Wea. Rev., 136, 1940-1956.

Jones, C., L. M. V. Carvalho, R. W. Higgins, D. E. Waliser, and J.-K. E. Schemm, 2004: A statistical forecast model of tropical intraseasonal convective anomalies. J. Climate, 17, 2078-2095.

Kang, I.-S., and H.-M. Kim, 2010: Assessment of MJO predictability for boreal winter with various statistical and dynamical models. J. Climate, 23, 2368-2378.

Kessler, W. S., 2001: EOF representations of the Madden-Julian oscillation and its connection with ENSO. J. Climate, 14, 30553061.

Koster, R. D., M. J. Suarez, A. Ducharne, M. Stieglitz, and P. Kumar, 2000: A catchment-based approach to modeling land surface processes in a general circulation model. 1: Model structure. J. Geophys. Res., 105 (D20), 24 809-24 822.

Kug, J.-S., Y.-G. Ham, M. Kimoto, F.-F. Jin, and I.-S. Kang, 2010: New approach on the optimal perturbation method for ensemble climate prediction with empirical singular vector (ESV). Climate Dyn., 35, 331-340, doi:10.1007/s00382-0090664-y.

_ — — E.-J. Lee, and I.-S. Kang, 2011: Empirical singular vector (ESV) method for ensemble ENSO prediction with a coupled GCM. J. Geophys. Res., 116, C08029, doi:10.1029/ 2010 JC006851.

Liess, S., D. E. Waliser, and S. D. Schubert, 2005: Predictability studies of the intraseasonal oscillation with the ECHAM5 GCM. J. Atmos. Sci., 62, 3320-3336.

Lin, S.-J., 2004: A vertically Lagrangian finite-volume dynamical core for global models. Mon. Wea. Rev., 132, 2293-2307.

Lo, F., and H. H. Hendon, 2000: Empirical extended-range prediction of the Madden-Julian oscillation. Mon. Wea. Rev., 128, 2528-2543.

Lock, A. P., A. R. Brown, M. R. Bush, G. M. Martin, and R. N. B. Smith, 2000: A new boundary layer mixing scheme. Part I: Scheme description and SCM tests. Mon. Wea. Rev., 128, 3187-3199.
Louis, J.-F., 1979: A parametric model of vertical eddy fluxes in the atmosphere. Bound.-Layer Meteor., 17, 187-202.

Madden, R. A., and P. R. Julian, 1971: Detection of a 40-50-day oscillation in the zonal wind in the tropical Pacific. J. Atmos. Sci., 28, 702-708.

Maharaj, E. A., and M. C. Wheeler, 2005: Forecasting an index of the Madden-Julian oscillation. Int. J. Climatol., 25, 16111618.

McFarlane, N. A., 1987: The effect of orographically excited gravity wave drag on the general circulation of the lower stratosphere and troposphere. J. Atmos. Sci., 44, 1775-1800.

Mo, K. C., 2001: Adaptive filtering and prediction of intraseasonal oscillations. Mon. Wea. Rev., 129, 802-817.

Molinari, J., D. Knight, M. Dickinson, D. Vollaro, and S. Skubis, 1997: Potential vorticity, easterly waves, and eastern Pacific tropical cyclogenesis. Mon. Wea. Rev., 125, 2699-2708.

Molteni, F., and T. N. Palmer, 1993: Predictability and finite time instability of the northern winter circulation. Quart. J. Roy. Meteor. Soc., 119, 269-298.

Moorthi, S., and M. J. Suarez, 1992: Relaxed Arakawa-Schubert: A parameterization of moist convection for general circulation models. Mon. Wea. Rev., 120, 978-1002.

Palmer, T. N., R. Buizza, E. Molteni, Y.-Q. Chen, and S. Corti, 1994: Singular vectors and the predictability of weather and climate. Philos. Trans. Roy. Soc. London, 348, 459-475.

Rashid, H. A., H. H. Hendon, M. C. Wheeler, and O. Alves, 2011: Prediction of the Madden-Julian oscillation with the POAMA dynamical prediction system. Climate Dyn., 36, 649-661.

Rienecker, M. M., and Coauthors, 2007: The GEOS-5 data assimilation system-Documentation of versions 5.0.1, 5.1.0, and 5.2.0. NASA/TM-2007-104606, Vol. 27.

_ rospective Analysis for Research and Applications. J. Climate, 24, 3624-3648.

Rotstayn, L. D., 1997: A physically based scheme for the treatment of stratiform clouds and precipitation in large-scale models. I: Description and evaluation of the microphysical processes. Quart. J. Roy. Meteor. Soc., 123, 1227-1282.

Seo, K. H., 2009: Statistical-dynamical prediction of the MaddenJulian oscillation using NCEP Climate Forecast System (CFS). Int. J. Climatol., 29, 2146-2155.

_ J. K. E. Schemm, C. Jones, and S. Moorthi, 2005: Forecast skill of the tropical intraseasonal oscillation in the NCEP GFS dynamical extended range forecasts. Climate Dyn., 25, 265 284.

—, W. Wang, J. Gottschalck, Q. Zhang, J.-K. E. Schemm, Y. R. Higgins, and A. Kumar, 2009: Evaluation of MJO forecast skill from several statistical and dynamical forecast models. J. Climate, 22, 2372-2388.

Slingo, J. M., and Coauthors, 1996: Intraseasonal oscillations in 15 atmospheric general circulation models: Results from an AMIP diagnostic subproject. Climate Dyn., 12, 325-357.

Smith, R. N. B., 1990: A scheme for predicting layer clouds and their water contents in a general circulation model. Quart. J. Roy. Meteor. Soc., 116, 435-460.

Takayabu, Y. N., T. Iguchi, M. Kachi, A. Shibata, and H. Kanzawa, 1999: Abrupt termination of the $1997 / 98$ El Niño in response to a Madden-Julian oscillation. Nature, 402, 279-282.

Tanaka, H. L., N. Ishizaki, and A. Kitoh, 2004: Trend and interannual variability of Walker, monsoon and Hadley circulations defined by velocity potential in the upper troposphere. Tellus, 56A, 250-269. 
Toth, Z., and E. Kalnay, 1993: Ensemble forecasting and NMC: The generation of perturbations. Bull. Amer. Meteor. Soc., 74, 2317-2330.

Vitart, F., and F. Molteni, 2010: Simulation of the Madden-Julian oscillation and its teleconnections in the ECMWF forecast system. Quart. J. Roy. Meteor. Soc., 136, 842-855.

—, S. Woolnough, M. A. Balmaseda, and A. M. Tompkins, 2007: Monthly forecast of the Madden-Julian oscillation using a coupled GCM. Mon. Wea. Rev., 135, 2700-2715.

Waliser, D. E., 2006: Predictability of tropical intraseasonal variability. Predictability of Weather and Climate, T. N. Palmer and R. Hagedorn, Eds., Cambridge University Press.

_ , and Coauthors, 2003a: AGCM simulations of intraseasonal variability associated with the Asian summer monsoon. Climate Dyn., 21, 423-446.

— , K. M. Lau, W. Stern, and C. Jones, 2003b: Potential predictability of the Madden-Julian oscillation. Bull. Amer. Me teor. Soc., 84, 33-50.

- , and Coauthors, 2006: The experimental MJO prediction project. Bull. Amer. Meteor. Soc., 87, 425-431.

Webster, P. J., and C. Hoyos, 2004: Prediction of monsoon rainfall and river discharge on 15-30-day time scales. Bull. Amer. Meteor. Soc., 85, 1745-1765.
Wheeler, M., and H. Hendon, 2004: An all-season real-time multivariate MJO index: Development of an index for monitoring and prediction. Mon. Wea. Rev., 132, 1917-1932.

_ _ and J. L. McBride, 2005: Australian-Indonesian monsoon. Intraseasonal Variability in the Atmosphere-Ocean Climate System, W. K. M. Lau and D. E. Waliser, Eds., Springer, 125173.

Wu, M. L., S. Schubert, I.-S. Kang, and D. Waliser, 2002: Forced and free intraseasonal variability over the South Asian monsoon region simulated by 10 AGCMs. J. Climate, 15, 28622880.

Xue, Y., M. A. Cane, and S. E. Zebiak, 1997a: Predictability of a coupled model of ENSO using Singular Vector analysis. Part I: Optimal growth in seasonal background and ENSO cycles. Mon. Wea. Rev., 125, 2043-2056.

$\longrightarrow,-$, and $-1997 \mathrm{~b}$ : Predictability of a coupled model of ENSO using singular vector analysis. Part II: Optimal growth and forecast skill. Mon. Wea. Rev., 125, 2057-2073.

Yasunari, T., 1979: Cloudiness fluctuations associated with the Northern Hemisphere summer monsoon. J. Meteor. Soc. Japan, 57, 227-242.

Zhang, C., 2005: Madden-Julian oscillation. Rev. Geophys., 43, RG2003, doi:10.1029/2004RG000158. 